\title{
LOS TRATADISTAS DEL EROS CONTRA LA ACADEMIA. EL CASO DEL SOCIÓLOGO AMANDO DE MIGUEL
}

\author{
EROS WRITERS AGAINST THE ACADEMY. THE CASE OF THE \\ SOCIOLOGIST AMANDO DE MIGUEL
}

Mirko LAMPIS

Constantine the Philosopher University in Nitra

mlampis@ukf.sk

Fecha de recepción: 06-10-2020

Fecha de aceptación: 21-11-2020

\section{RESUMEN}

El objetivo de este ensayo es estudiar el tratamiento que el sociólogo Amando de Miguel, uno de los autores que se han ocupado de la cultura erótica en España, reserva a las definiciones del Diccionario de la lengua española de la RAE. Se analizarán los comentarios y juicios que Miguel, en su obra El sexo de nuestros abuelos (1998), dirige a las definiciones de la vigésima primera edición del Diccionario. El sociólogo aplica aquí la misma estrategia meta-discursiva que ya aparece en La perversión del lenguaje (1994), su primera obra de género «dardesco», y critica la «pudibundez» del diccionario académico y sus desfases o desajustes con respecto al uso de la lengua. Hay que reconocer, sin embargo, que esta «pudibundez», señalada con gran ironía en la obra de Miguel, ha menguado en las últimas ediciones del repertorio académico, debido a una mayor libertad o liberalidad cultural en las prácticas y los discursos acerca de la sexualidad y a una práctica lexicográfica que tiende cada vez más a la neutralidad axiológica.

Palabras Clave: erotismo; Amando de Miguel; Diccionario de la lengua española; RAE Abstract

The goal of this paper is to study how the sociologist Amando de Miguel, one of the authors who have looked into erotic culture in Spain, values the definitions of RAE's 
Dictionary of Spanish (Diccionario de la lengua española). Focusing on the work El sexo de nuestros abuelos (1998), we will analyze de Miguel's comments and judgments about the definitions of the twenty-first edition of the Dictionary. The sociologist applies here the same meta-discursive strategy which he used in La perversión del lenguaje (1994), his first «dartesque» genre work, and criticizes the «prudishness» of the academic dictionary and the discrepancy between its definitions and the linguistic use. It must be admitted, however, that this «prudishness», pointed out with great irony in de Miguel's book, diminished in later editions of the academic dictionary, because of a greater cultural freedom in the practices and discourses about sexuality, and a lexicographic praxis that increasingly tends to axiological neutrality.

KeY Words: eroticism; Amando de Miguel; Dictionary of Spanish; RAE

\section{PROLEGÓMENOS}

Mucho se ha ironizado, y sigue ironizándose, acerca del lema de la Real Academia Española, que puede recordar a la conciencia contemporánea el eslogan publicitario de un detergente o de un champú ${ }^{1}$. En todo caso, y al margen de fáciles ironías, hay que reconocer que la voluntad de limpiar, fijar y dar esplendor al idioma, perfectamente justificada en 1715, cuando apareció el emblema de la Academia y, con él, el lema que lo corona, choca hoy día con una serie de supuestos teóricos generalmente aceptados (o al menos tolerados) en el ámbito de los estudios linguiísticos. A saber: las lenguas son fenómenos heterogéneos (y, por ende, impuros) que cambian en el tiempo (sin poderse fijar) y presentan múltiples registros y funciones (algunos más «intelectualizados» que otros, pero todos legítimos).

Sabemos bien que existen, en el devenir de un idioma, tanto procesos «centrípetos» (centralizadores), que apuntan a la normativización e institucionalización, como procesos «centrífugos» (dispersivos) hacia la idiosincratización y contextualización y que el estado del idioma en un momento dado depende del juego relacional que se establece entre ambas series de procesos ${ }^{2}$. Los lingüistas, por lo común, reconocen la importancia y estudian los efectos tanto de los procesos centrípetos como de los centrífugos, lo que no impide, sin embargo, que, según el momento, el lugar y la función del trabajo que se desempeñe, cobren más protagonismo, más relevancia explicativa, e incluso más dignidad idiomática,

1 La broma, según recuerda Lázaro Carreter (2003: 692), circulaba entre los mismísimos académicos. Véase también, como curiosidad, el divertido (y criticado) anuncio que la Academia de la Publicidad le dedicó a la RAE en 2013, en ocasión del tercer centenario de la institución (https://www.youtube.com/watch?v=imiJMIYx1zQ).

2 No se pueden identificar, sin más, las «fuerzas centrífugas» con las tendencias espontáneas del habla y las «centrípetas» con las políticas lingüísticas oficiales llevadas a cabo por gobiernos, instituciones, academias, etc. La formación de un pidgin o de un criollo, por ejemplo, es un proceso espontáneo de tipo «centrípeto», mientras que la política lingüística que impone el uso oficial de un idioma en un territorio de habla diferente es un proceso programado de tipo «centrífugo». Incluso el caso más sencillo — el de una lengua normativizada concreta (digamos la llamada «norma culta peninsular» del español) sobre la que actúan diferentes y contrarias fuerzas conservadoras e innovadoras - presenta movimientos de base que cuentan con un fuerte y espontáneo sentido de pulcritud idiomática e identidad lingüística y elites culturales que empujan hacia mayores libertades expresivas. 
los primeros o los segundos. Permítaseme citar dos observaciones que ejemplifican, según creo, estas diferentes maneras de presentar las dinámicas lingüísticas.

La primera observación la debemos a la pluma de Fernando Lázaro Carreter, insigne lingüista y filólogo, director de la RAE desde 1991 hasta 1998 y autor de una serie de pequeños artículos divulgativos, los dardos, dedicados a reprender los abusos lingüísticos perpetrados por los profesionales de la palabra (sobre todo los periodistas de la prensa, la radio y la televisión). Al rechazar toda posible asociación entre su labor de censor de los malos usos del español y las corrientes puristas y casticistas de la lengua, escribe don Fernando:

Más o menos atenuadas, ambas vetustas tendencias [el casticismo y el purismo] subsisten, justamente desdeñadas, pero se aprovechan sus nombres para descalificar sin razón aquellas otras que desean evitar al idioma cambios arbitrarios o disgregadores, con el fin de que pueda seguir sirviendo para el entendimiento del mayor número posible de personas durante el mayor tiempo posible. En tal sentido proceden o deberían proceder la escuela, la lengua escrita literaria o no, la oratoria en todas sus manifestaciones y, por supuesto, las Academias (LÁZARO CARRETER, 2003: 20).

La segunda observación es del profesor Enrique Bernárdez, de la Universidad Complutense de Madrid:

Académicos, profesores, maestros, periodistas, incluso aficionados, claman [...] contra los errores del lenguaje que destruyen la lengua castellana («la más hermosa del mundo»). Normalmente tienen tanta razón como un santo... como un santo que condena a alguien a la hoguera por decir que la tierra es redonda, o que damos vueltas alrededor del sol, o que el ser humano ha evolucionado a partir de un antecesor común a nosotros y a los chimpancés. En otras palabras, no tienen razón. Sólo una concepción de la lengua estándar como propiedad exclusiva de alguna institución o algún otro ente semejante permite afirmar cosas parecidas (BERNÁRDEZ, 2012: 47).

A pesar del signo opuesto de las dos citas, Lázaro Carreter y Bernárdez coinciden en lo más importante: las lenguas son fenómenos dinámicos, sincréticos y estratificados, de modo que «hablar bien», «hablar con propiedad y corrección», significa sobre todo poder comunicar de forma adecuada y eficaz en los diferentes contextos y situaciones de interacción social. El problema, más bien, estriba en que es muy distinta la postura de los dos autores acerca de la labor que han de desempeñar las instituciones lingüísticas (escuelas y academias en primer lugar). Según Lázaro Carreter, estas instituciones, al igual que los hablantes y escribientes públicos y, en definitiva, todos los hablantes y escribientes responsables, tienen el deber (y aun la misión) de evitar que el idioma español, heredero de una venerable tradición y hablado por una comunidad internacional, sufra cambios innecesarios, en su dimensión culta, a raíz de la laxitud y la torpeza de muchos de sus representantes ${ }^{3}$.

3 El miedo a la «desnaturalización» del idioma es un fenómeno social bastante extendido, por lo menos si consideramos la gran cantidad de libros y papeles dedicados al tema (sobre todo obras «dardescas» y manuales y libros de estilo). Además de El dardo en la palabra de Lázaro Carreter, me gustaría recordar La perversión del lenguaje, de Amando de Miguel (1994), y Defensa apasionada del idioma español, de Álex Grijelmo (2001). A veces, tales obras presentan un panorama desolador. Miguel (1994: 11) abre su libro con estas palabras: «Este es 
Según Bernárdez, en cambio, nadie puede arrogarse el derecho de estigmatizar un determinado uso lingüístico tan solo porque este no se ajusta a las normas y regularidades seleccionadas y establecidas a nivel institucional y político. En toda lengua, en todo momento, hay variantes y oscilaciones ${ }^{4}$.

En cuanto a la postura oficial de la RAE, por si alguien tuviera alguna duda al respecto, es suficiente consultar el artículo 1 de los Estatutos de la Real Academia Española, promulgados en 1993, donde se puede leer lo siguiente:

La Academia es una institución con personalidad jurídica propia que tiene como misión principal velar por que los cambios que experimente la Lengua Española en su constante adaptación a las necesidades de sus hablantes no quiebren la esencial unidad que mantiene en todo el ámbito hispánico. Debe cuidar igualmente de que esta evolución conserve el genio propio de la lengua, tal como ha ido consolidándose con el correr de los siglos, así como de establecer y difundir los criterios de propiedad y corrección, y de contribuir a su esplendor. ${ }^{5}$

Como se ve, la insistencia en los cambios y en la evolución del idioma corre pareja a la necesidad de defender «su unidad esencial», «su genio», «sus criterios de corrección y propiedad» y «su esplendor». ¿Mera casualidad, por cierto, que el viejo lema y el nuevo propósito terminen con la misma metáfora luminosa?

un ensayo satírico, escrito desde la A a la Z, entre el amor y la zozobra que me produce asistir a la dilapidación del capital más valioso del que dispongo: la lengua castellana». Grijelmo, en el primer capítulo de su libro, titulado «Una lengua en deterioro», declara que se ha perdido la vergüenza por no escribir bien, condena la falta de respeto por el patrimonio idiomático común, señala errores (como el sintagma «perjudica seriamente la salud», que debería ser «perjudica gravemente a la salud») que acaban perjudicando gravemente al idioma y denuncia: «El deterioro de la lengua que se emplea en público ha llegado al hecho, impensable en otras épocas, de que incluso algún miembro de la Real Academia Española escriba de manera pedestre» (GRIJELMO, 2001: 25).

4 Palabras y expresiones que antaño los hablantes cultivados consideraban como incorrectas, incultas o peregrinas, son hogaño parte estable de la lengua estándar o de la norma culta, y palabras y expresiones percibidas en su día como cultismos suenan hoy como vocablos corrientes ( «los cultismos acaban bajando al pueblo», comenta Miguel, 1991: 91). Raramente, sin embargo, y esto es lo que vale la pena destacar, una forma lingüística se impone en el uso y finalmente en la norma por un proceso de difusión lineal. Las formas normativizadas y las «incorrectas» suelen convivir. Un ejemplo. En los años cincuenta ya existe en la lengua escrita la forma verbal prevee, inexistente según la lengua normativizada (MIGUEL, 1991: 96). Hoy día, más de setenta años después, sigue encontrándose la misma forma, pese a los esfuerzos enmendadores de los intelectuales y hablantes cultivados y a la lógica que impone que un verbo derivado respete la conjugación del verbo derivante (ve, luego prevé [y no prevee]; vio, luego previó [y no preveyó]). En estos casos, apunta Bernárdez (2012: 47-48), «estamos en una fase de cambio, de evolución» y nadie puede prever a ciencia cierta qué forma acabará ganando terreno. ¿Y si ninguna lo hiciera? Seguirá habiendo, entonces, quienes digan y escriban prevee y quienes critiquen tal uso en nombre de la corrección y la pulcritud del idioma. Vale, al respecto, la siguiente y muy sensata observación de Antonio Narbona Jiménez: «La tensión entre diversidad y unidad, entre fuerzas centrípetas y centrífugas, entre lo que debería ser y lo que es, no se resolverá jamás. Pero sí merece la pena que todos nos empeñemos en acortar la distancia idiomática (las otras, también, por supuesto) que separa a los diferentes sectores de la sociedad, única forma de atenuar la discriminación que deriva de su distinta y desigual competencia lingüística» (NARBONA JIMÉNEZ, 2001).

5 Se pueden consultar los Estatutos en la página web de la RAE (https://www.rae.es/sites/default/files/2020-07/Estatutos\%20y\%20reglamento_2014_Modificado_2020.pdf) y, asimismo, en el Boletín Oficial del Estado (https://www.boe.es/eli/es/rd/1993/07/09/1109/con). 
En un dardo de 1986, Lázaro Carreter comenta con preocupación e ironía una proposición del Parlamento con la que el órgano legislativo invitaba a la RAE a «eliminar [del Diccionario] todos los términos atentatorios contra la condición femenina»:

Nuestros legisladores han probado con tal decisión su voluntariosa capacidad resolutiva: basta con eliminar el espejo para que la fealdad se esfume. Justamente el espejo ha sido tomado muchas veces como término de comparación para explicar cómo el lenguaje reproduce pensamientos y actitudes de la sociedad que lo habla, reflejándolos. Pero nadie, hasta ahora, había pensado que pudiera ocurrir lo contrario, y que destruyendo la imagen desapareciese lo reflejado por ella (LÁZARO CARRETER, 2003: 396).

El cometido del Diccionario de la lengua española es el de registrar con la máxima fidelidad posible los usos léxicos del idioma español, así que, si algo socialmente «feo» queda recogido en sus páginas, es porque esa «fealdad» está presente en la sociedad y, de reflejo, en el idioma. Pero Lázaro Carreter en ningún caso comenta, que yo sepa, la posibilidad de que se dé el caso contrario, a saber, que se evite recoger en el diccionario de la Academia términos y acepciones que reflejan realidades y nociones moralmente incómodas desde el punto de vista de la cultura oficial española, alineada, por tradición, con los valores del patriarcado, el catolicismo y el elitismo (dicho sea, desde luego, sin ánimo de polemizar: solo se trata de recordar que hablamos de una cultura académica «hecha» por y para hombres, patres familias y creyentes, amén de exponentes de la elite cultural y económica). Sería este último, sin embargo, el caso que vamos a presentar a continuación: el de las voces relacionadas con la sexualidad y las prácticas sexuales.

En un reciente artículo (LAMPIS, 2020b) he tratado, entre otras cosas, de seguir la historia lexicográfica de un corpus de voces relacionadas con el erotismo ${ }^{6}$. Los resultados de este estudio han sido, grosso modo, los siguientes:

1) La mayoría de derivas semánticas detectadas apuntan a la neutralización y generalización de las definiciones: se tiende a eliminar los juicios de valor y los términos que «encuadran» moralmente a las voces definidas (vicio, pecado, contra natura, ilícito, exagerado, etc.) y se tiende, asimismo, a registrar nuevas acepciones de forma más concisa y con un más amplio dominio referencial. Esto era lo previsible, considerando las transformaciones experimentadas por la sociedad católica y burguesa (en cuanto a la materia tratada) $)^{7}$ y los avances en el campo de la lexicografía (en cuanto a la modalidad de tratamiento).

2) En el corpus estudiado, la noción o, mejor dicho, el interpretante central, por lo menos hasta finales del siglo Xx, es el de 'carnalidad': «acto carnal», «ayuntamiento

6 Concretamente, las siguientes voces: amor, coito, cópula, erotismo, fornicación, heterosexualidad, homosexualidad, libido, lujuria, pornografía, seducción, sexo, sexualidad, transexualidad, voluptuosidad.

7 Tales transformaciones, en Europa y Norteamérica, se vuelven particularmente relevantes a partir de la revolución sexual de los años sesenta (movimientos beatnik y hippy, ideal del amor libre, feminismo, derechos de los homosexuales, píldora contraceptiva, boom económico, etc.). En España, la nueva ola empieza a notarse a partir de la segunda mitad de los años setenta, con la paulatina vuelta a las libertades democráticas. Esto también tiene efectos a nivel lexicográfico, con enmiendas sustanciales en las definiciones de las voces del eros en las ediciones de 1984 y 1992 del diccionario académico. 
carnal», «juntarse carnalmente», «deleites de la carne». Hay que tener en cuenta, en este caso, la polaridad semántica entre 'espíritu' y 'carne', fundamental para la ideología cristiana, donde la 'carne', claro está, representa el polo negativo: prisión, esclavitud, descontrol, vicio, pecado, perdición. Solo en época reciente, las definiciones dejan de referirse a la carnalidad para relacionarse, de forma más neutral pero también más ambigua, con la sexualidad.

3) Los diccionarios estudiados presentan evidentes desfases semánticos internos debidos a la reticencia a explicitar, para definir una actividad considerada como «privada», «íntima» o «indecente», determinadas características a las que, sin embargo, se alude en la definición de las voces relacionadas.

4) Los diccionarios relacionan de forma explícita el erotismo con la pasión amorosa (aunque violenta o exacerbada) y con la sensualidad/sexualidad; con el paso del tiempo, no obstante, se manifiesta una clara tendencia a resaltar sobre todo la relación entre lo erótico y lo sexual. Hay un desequilibrio evidente, además, en las estrategias definitorias: mientras las voces erotismo y amor remiten con frecuencia al sexo, las definiciones de sexo no contienen ninguna referencia al amor o al erotismo (cabe recordar, por cierto, que sexual y sexo se refieren, en primer término, a las diferencias orgánicas entre machos y hembras, mientras que el acto sexual y la actividad sexual entran en el diccionario académico solo en 2001 y 2014, respectivamente).

5) Los diccionarios definen la voz erotismo principalmente a través de una modelización específica del amor y la sexualidad. Sus estrategias definitorias no son, por ende, ajenas al hecho de que tanto el placer carnal (físico, sensual, sexual) como el deseo amoroso (anhelo de completitud por comunión) se relacionan con la doble dimensión estética del erotismo: la cura por las sensaciones del cuerpo - y por las identidades sentidas y sintientes - y la cura por la belleza de las formas y los modos experimentados ${ }^{8}$.

Es a este panorama lexicográfico al que quiero ahora volver, esta vez con el objetivo de examinar el tratamiento que reservan a las definiciones académicas dos de los principales autores que se han ocupado del erotismo en España: el escritor Camilo José Cela, con su monumental Enciclopedia del erotismo (de 1976), y el sociólogo Amando de Miguel, con su monografía El sexo de nuestros abuelos (de 1998). Me ocuparé, aquí y ahora, de este último autor, reservándome para más adelante el estudio de la enciclopedia de Cela.

8 Como se ha defendido en Lampis (2020A), al erotismo es un repertorio cultural de procesos, recursos y elementos expresivos cuyo efecto (y, a menudo, cuya función también) es resaltar y exaltar la dimensión estética de la interacción amorosa (con sus atracciones, contactos y rechazos). Dimensión estética porque relativa a lo bello - y, por ende, a un sistema de canonización de las formas experimentadas- y, asimismo, porque relativa a la aísthesis, la sensación (y al sentido de identidad que de esta se deriva: yo soy quien siente atracción y repulsión). 


\section{AMANDO DE MIGUEL Y LA SUTIL ARMA DE LA IRONÍA}

Muchas de las observaciones que Amando de Miguel recoge en La perversión del lenguaje, libro dedicado a reprender determinados usos erróneos, someros o imprecisos de la lengua española, versan sobre el desfase existente entre las definiciones del diccionario de la RAE y la realidad idiomática de los hablantes ${ }^{9}$. El motivo lo deja bien claro el autor:

He citado el DRAE, que es la suprema instancia en los pleitos de la lengua común española. Varias veces recurrimos a él y a otros lexicones. No se crea que con ello quedan zanjadas las cuestiones lingüísticas. Los diccionarios registran el idioma y este evoluciona con la sociedad, aunque, como vamos a ver, los ritmos no sean coincidentes. El diccionario lo hacemos entre todos. Sus incongruencias son las de la vida colectiva. Los académicos de la Real Española están hechos de la misma pasta que el resto de los hombres públicos (MIGUEL, 1994: 23).

Introduce así Miguel un nuevo elemento en el género «dardesco» (permítaseme llamarlo así en honor a los dardos de Lázaro Carreter): no solo hay que reprender los abusos idiomáticos perpetrados por los hablantes y escribientes (sobre todo los profesionales de la pluma y del micro), sino también los errores y olvidos de los lexicógrafos.

Me parece oportuno citar por lo menos uno de los comentarios de Miguel. Elijo uno relativo a una expresión decididamente pertinente con el tema del presente ensayo y que nos ayudará e introducir, de paso, el estilo del autor. Al hablar de castidad conyugal, escribe Miguel:

El DRAE de 1984 nos dice que es «la que se guardan mutuamente los casados», siendo la castidad «virtud que se opone a los efectos carnales». Es posible que determinados cónyuges se opongan a los efectos carnales, pero no parece muy razonable que su acción pueda entenderse como «virtud», esto es, como recto y aconsejable modo de proceder. La versión de 1992 precisa que la «castidad» es la «virtud del que se abstiene de todo goce carnal». Sigue sin entenderse cómo pudo ser una virtud de los casados. (MIGUEL, 1994: 167) ${ }^{10}$

Yo diría, aun a riesgo de equivocarme, que la ironía del comento es evidente. Y la ironía, el sarcasmo y la socarronería (para utilizar un término retóricamente quizá más acertado) son, como veremos, marca de la casa.

Claro que las críticas de Miguel no siempre suenan tan irónicas o socarronas. No lo son, por ejemplo, al comentar nuestro autor la voz impotencia. Resulta que aún en la edición de 1984 del Diccionario, tras una primera acepción general ( «1. Falta de poder para hacer una cosa»), se define la famosa disfunción varonil como «incapacidad de engendrar o concebir». Eso, apunta escuetamente Miguel, sería más bien la esterilidad, mientras que

9 Señalo de paso que aquellos lingüistas o sociólogos que hablan de «realidad idiomática», entendiendo con ello, al parecer, la manera en que habla la gente corriente en el transcurso de su vida cotidiana, llevan a cabo una operación abstractiva no muy diferente de la de quienes hablan de norma culta o de estándar.

10 En la última edición del Diccionario, todavía se menciona la castidad conyugal en los mismos términos comentados por Miguel, pero la definición de la castidad como «virtud de quien se abstiene de todo goce carnal» ha pasado en segundo lugar, siendo precedida por una primera acepción mucho más neutral: «1. f. Cualidad de casto». 
la impotencia es la «incapacidad de la erección del pene a su debido tiempo»; hasta este punto, concluye nuestro autor, «llega la influencia ideológica de la Iglesia Católica, la sustentadora de la no separación entre los planos de sexo y procreación» (MIGUEL, 1994: 167-168). En honor de la verdad, hay que decir que en este caso Miguel se muestra quizá demasiado duro con la Academia, pues escribe que no le parece justificado que en el Diccionario de 1992 no se haya corregido todavía el error, cuando, en efecto, justamente en esa edición aparece una tercera acepción «enmendadora»: «imposibilidad en el varón para realizar el acto sexual completo». Definición vaga y eufemística, ciertamente, pero algo es algo ${ }^{11}$.

Ahora bien, si el diccionario de la Academia es una referencia constante en La perversión del lenguaje, algo obvio considerando el argumento del libro, su papel en las demás obras miguelianas es sin duda menor, marginal o inexistente ${ }^{12}$. Con una interesante excepción: El sexo de nuestros abuelos, de 1998, el libro que aquí nos interesa. Este versa sobre los cambios que experimentó en España la cultura sexual y erótica en las primeras décadas del siglo xx y ciertamente no abundan, entre sus páginas, las referencias al Diccionario. Pero su misma estructura diccionarial — es decir, por lemas ordenados alfabéticamente; la misma estructura, por cierto, de La perversión del lenguaje - y la tipología de las críticas miguelianas invitan a un trabajo de tipo analítico y comparativo.

Si mis cuentas no yerran, en El sexo de nuestros abuelos Miguel cita el diccionario académico o se refiere a la labor de la Academia solo diez veces. La mitad de las citas y referencias, además, se concentran en un único capítulo, el dedicado a la entrada modas, y dos se refieren al mismo vocablo (panti). Vale la pena leer los pasajes correspondientes. Téngase en cuenta que la edición del Diccionario de la lengua española consultada por Miguel es la vigésima primera, de 1992.

i) Para empezar, recuérdese la múltiple función de la lengua: «Órgano muscular situado en la cavidad de la boca de los vertebrados y que sirve para gustar, para deglutir y para articular los sonidos de la voz» (DRAE). Al pudibundo lexicón oficial se le ha pasado por alto que ese dichoso órgano es uno de los más sensibles al tacto. De ahí que, para los humanos, encierre también la secreta función de cooperar al placer sexual (MIGUEL, 1998: 28; s.v. aclaración).

ii) [...] la expresión actual «hacer el amor» como poseer, copular. Es otro galicismo, pero de nuestra época. Por cierto, el DRAE ya ha añadido esta última acepción,

11 En la edición del Diccionario de 2001, esta tercera acepción se transforma en «imposibilidad en el varón para realizar el coito», acepción que finalmente pasa en segundo lugar en la última edición de 2014, donde de todas formas se sigue conservando, en tercer lugar, la definición criticada por Miguel.

12 También el último libro de Miguel, Hablar pronto y mal (2013), versa sobre determinadas oscilaciones, transformaciones y usos irreflexivos, empobrecidos y a menudo malamente estereotipados del español hablado y escrito, sobre todo en el ámbito del «politiqués», la lengua empleada por políticos y periodistas. Pero en esta obra nunca se trae a colación la autoridad del diccionario académico (es, en este sentido, más típicamente «dardesca»). Sí hay unas cuantas referencias a la labor de la Real Academia Española, pero solo para recordar que, en los hechos de la lengua, el uso manda y no hay autoridad que se le resista. 
que es la única que conocen todos los demás contemporáneos (MIGUEL, 1998: 49; s.v. amor).

iii) El rígido corsé cede lugar a la faja elástica, el vistoso pantalón con puntillas da paso al culotte, luego a las bragas y en nuestro tiempo a la «braguita». (Todavía no la han descubierto los señores del DRAE.) (MIGUEL, 1998: 133; s.v. modas).

iv) La tradición española era la de sujetar las medias por debajo de la rodilla. La moda francesa impone la norma de subir las medias hasta el muslo. La última edición del DRAE evita la polémica. Liga es la «cinta o banda de tejido elástico, a veces con hebilla, para asegurar la media o los calcetines». Obsérvese el pudibundo singular de «media» frente al plural de «calcetines» (MIGUEL, 1998: 139; s.v. modas).

v) [...] el tejido inconsútil de los pantis (el DRAE último no saben que existen) no ha conservado el alto atractivo erótico de las antiguas medias con costuras (MIGUEL, 1998: p. 139; s.v. modas).

vi) Con la minifalda se exige el panti, tan misterioso, que, como queda dicho, todavía no lo conocen los actuales académicos de la Lengua. [...] El DRAE se ha quedado con los circenses leotardos, que ejercen la misma función pudorosa de unas medias incorporadas a las bragas para sujetarse en la cintura (MIGUEL, 1998: 142; s.v. modas);

vii) $[\ldots]$ el DRAE sostiene hoy todavía que el viso es un «forro de color o prenda de vestido que se coloca debajo de una tela clara para que por ella se transparente». No es eso, sino más bien lo contrario. Su función es la de evitar que se transparenten las piernas, el regazo o los glúteos a través de la falda (MIGUEL, 1998: 146; s.v. modas).

viii) Novio viene de novus maritus, es decir, recién casado. Todavía se emplea este sentido, que muchos consideran absurdo [...] Pero la significación más corriente es la tercera del DRAE, aunque insuficiente: «persona que mantiene relaciones amorosas en expectativa de matrimonio». Hay que añadir un dato fundamental: esas relaciones son estables y respecto a una sola persona (MIGUEL, 1998: 173174; s.v. noviazgo).

ix) El DRAE señala todavía la doble significación [de galante] según el género del sujeto. Un varón es galante cuando se manifiesta como «atento, cortés, obsequioso, en especial con las damas». Pero el adjetivo "aplícase a la mujer... de costumbres licenciosas». De forma menos púdica, en el habla del principio del siglo XX, lo «galante» femenino era la pertenencia a la prostitución cara (MIGUEL, 1998: s.v. seducción).

x) La seducción presenta dos significados bastante diferentes. Por un lado, indica un «engaño, con arte y maña», dice el DRAE. A lo cual habría que añadir el propósito más literal, el de conseguir el favor sexual de una persona. El otro sentido menos violento y pasivo es el de «embargar o cautivar el ánimo» (DRAE), se sobreentiende también, con miras a resaltar el atractivo sexual (MIGUEL, 1998: s.v. seducción).

Queda claro que Miguel reconoce, tanto en La perversión del lenguaje como en El sexo de nuestros abuelos, la autoridad del diccionario académico. Como también queda claro 
que las ironías y las críticas del sociólogo apuntan sustancialmente a tres características estructurales del trabajo de la Academia:

— la «pudibundez» del Diccionario (es decir, la tendencia a evitar referencias y definiciones explícitas en materia sexual): i, iv, ix, $\mathrm{x}$.

- el retraso con que se registran (o no se registran aún) determinadas voces y acepciones: ii, iii, v, vi;

— la imprecisión de algunas definiciones: vii, viii.

Cabe destacar, sin embargo, que no todos los comentarios y juicios de Miguel parecen justificados y, más importante aún, que algunos de los errores que él subraya en la edición de 1992 del Diccionario fueron subsanados en las dos ediciones siguientes, la de 2001 y la de 2014 (actualizada en línea a 2019). Permítaseme, pues, comentar uno por uno los pasajes miguelianos.

i) Todavía la Academia (y ahora la Asociación de Academias) no se ha resuelto a incluir entre las características definitorias de la lengua, así como sugiere Miguel, la gran sensibilidad táctil y sensoria de este órgano, como tampoco sus usos eróticos. Tal vez debería hacerlo. $\mathrm{O}$ al menos especificar que la lengua, además de gustar, deglutir y articular sonidos, también sirve para lamer. Y para besar.

ii) Efectivamente, la edición de 1984 del Diccionario recoge, para la locución verbal hacer el amor, calcada del francés, solo el significado de «enamorar, galantear», y solo en la edición de 1992 aparece «copular» como segunda acepción, luego transformada, en 2001, en «copular (\| unirse sexualmente)». Quién sabe qué comentaría Miguel, al enterarse de que la «única acepción que conocen todos los demás contemporáneos» también en el siglo XXI sigue siendo, según los académicos, una segunda acepción.

iii) A la voz braguita todavía no se le ha concedido el honor de entrar en el caudal léxico del Diccionario. ¿Ignorarán aún — cabe preguntarse— «los señores del DRAE» su existencia? Si es así, no son los únicos. Evidentemente, la naturaleza diminutiva del lexema, junto al hecho de que la voz bragas ya se usa poco como sinónimo de calzones, desaconseja su registro y ni el diccionario general de Seco, Andrés y Ramos (1999) ni el diccionario especializado de Rodríguez González (2011) la recogen.

iv) Es dudoso que la definición del diccionario pueda o deba precisar a qué altura hay que colocar la liga, si por debajo o por encima de la rodilla. En cuestiones de moda, como se sabe, toda prudencia lexicográfica es poca, porque las modas son, por definición, lo más efímero y variable que se pueda imaginar. Habría que procurar, sin embargo, que la prudencia no se vuelva excesiva (convirtiéndose en desconfianza), lo que parece ser el caso de la voz comentada a continuación.

v-vi) La voz panti ha entrado en la última edición del Diccionario como «1. Prenda femenina, a modo de leotardo de tejido fino y muy elástico» y «2. Am. Cen., Col., Pan., P. Rico, R. Dom. y Ven. braga (\| prenda interior)». Considerando que la prenda en cuestión es de uso común por lo menos desde los años ochenta, y que ya se encuentra registrada (con la grafía panty) en el diccionario de Seco, Andrés 
y Ramos (1999), sí se puede decir que la Academia ha tardado quizá demasiado en oficializar su existencia. Cabe subrayar, por cierto, el valor casi profético de las palabras de Miguel: a fin de cuentas, parece cierto que los académicos tienen cierta predilección por los leotardos.

vii) La acepción de viso comentada por Miguel no ha cambiado en las dos últimas ediciones del Diccionario. La crítica del sociólogo a la definición es, quizá, demasiado tajante: sostener que la función del viso es la de transparentarse por debajo de una tela clara o la de que no se transparenten piernas y glúteos por debajo de la misma tela, es en el fondo sostener lo mismo. Eso sí, en términos muchos menos «carnales» en el primer caso.

viii) Miguel cita la tercera acepción de la definición de novio de forma ligeramente incorrecta, ya que la edición de 1992 especifica que el novio tiene una relación amorosa «en expectativa de futuro matrimonio». En 2001, el juego definitorio cambia sustancialmente: «1. Persona que acaba de casarse. 2. Persona que mantiene relaciones amorosas con fines matrimoniales. 3. Persona que mantiene una relación amorosa con otra sin intención de casarse y sin convivir con ella». En la última edición del Diccionario, finalmente, la definición se actualiza en: «1. Persona que mantiene relaciones amorosas con otra con fines matrimoniales. 2. Persona que va a casarse o acaba de casarse. 3. Persona que mantiene una relación amorosa con otra». En este caso, de todas formas, la glosa de Miguel a la definición académica no parece del todo necesaria: la exigencia de que la relación sea estable y con una sola persona queda implícita en la expresión «en expectativa de matrimonio».

ix) La primera acepción de galante de la edición de 1992 («1. Atento, cortés, obsequioso, en especial con las damas») llega inalterada hasta nuestros días; la segunda acepción ( $\ll 2$. Aplícase a la mujer que gusta de galanteos, y a la de costumbres licenciosas»), en cambio, se desdobla en las dos ediciones sucesivas: «2. Dicho de una mujer: Que gusta de galanteos. 3. Dicho de una mujer: De costumbres licenciosas». Un ejemplo más, si se quiere, de uso sexista de la lengua, pero justamente registrado en el diccionario si, como sostiene Miguel, en la primera mitad del siglo xx se llamaba, de forma harto eufemística, mujer galante a la prostituta de lujo. Seco, Andrés y Ramos (1999) ofrecen, de todas formas, una mejor solución definitoria: «3. (hoy raro) [Vida] de prostitución».

x) En la edición del Diccionario de 2001, a las dos acepciones de la voz seducir comentadas por Miguel se les añade una tercera, puesta estratégicamente entre las otras dos: «2. Atraer físicamente a alguien con el propósito de obtener de él una relación sexual». Se vuelve más explícito, pues, ese «propósito literal» de la seducción al que aludía Miguel. Más opinable, en cambio, me resulta el comentario de Miguel a la segunda (ahora tercera) acepción («embargar o cautivar el ánimo»), puesto que en este caso no siempre la finalidad de la seducción es de naturaleza sexual (y puede que erótica tampoco).

Miguel, podemos concluir, aplica con provecho a la materia objeto de El sexo de nuestros abuelos la misma estrategia metadiscursiva llevada a cabo, también con provecho, en 
La perversión del lenguaje. Sin embargo, si en el caso de este último libro dicha estrategia era funcional al argumento tratado, obviamente no lo es tanto en el caso del primero. El sexo de nuestros abuelos versa sobre la cultura erótica española de comienzos del siglo xx, mientras que las chanzas miguelianas contra la Academia tienen como blanco la edición de 1992 del Diccionario ${ }^{13}$. Por ello, las observaciones lingüísticas de Miguel son aquí esporádicas y circunstanciales. Lisa y llanamente, se trata de echarle un vistazo, de vez en cuando, al lexicón de la RAE para averiguar dónde se han quedado parados los académicos.

Cambiando los roles de la famosa paradoja de Zenón, decirse podría que la RAE (y ahora también la ASALE) es un poco como la «tortuga» lexicográfica que persigue al «Aquiles pie veloz» del idioma. Y si este, en el relato zenoniano, no conseguía alcanzar a aquella, la operación inversa parece aún más problemática. El juego de los adverbios en los pasajes miguelianos que hemos seleccionado apenas merece ser comentado: ya aparece una sola vez (en ii) y se diría que adquiere, irónicamente, el sentido de «por fin». En cambio, todavía aparece cinco veces, para subrayar que algo no está (y debería estar) o que algo sigue (y no debería seguir). La Academia va con retraso.

Por otro lado, los comentarios de Miguel apuntan a algo más que al desfase existente entre las definiciones académicas y el uso, desfase justificable, al fin y al cabo, acudiendo a la legítima prudencia (cuando no desconfianza) lexicográfica y a la continuidad histórica de las ediciones del diccionario de la RAE. Aunque no tenemos ningún caso parecido al de la definición de impotencia, para la que Miguel, en La perversión del lenguaje, llama en causa la «influencia ideológica de la Iglesia Católica» y la forzada identificación entre sexo y procreación (véase supra), también el uso del adjetivo pudibundo en dos ocasiones (i y iv) resulta sumamente indicativo. Nótese que esta voz culta significa «de mucho pudor» (en la edición de 1992 del Diccionario así como en la última). Pudor es (en la edición de 1992 así como en la última) «honestidad, modestia, recato». Recato es, en su primera acepción, «cautela, reserva» y el verbo recatar es «encubrir u ocultar lo que no se quiere que se vea o se sepa». Si el lexicón de la Academia es pudibundo, queda implícito que encubre u oculta algo, justamente lo que un diccionario no debería hacer. Ni siquiera en materia de «honestidad», es decir, de «decencia»y «decoro».

\section{CONCLUSIONES}

Tiempo al tiempo, parece casi necesario aconsejar a quienes se preocupan en demasía por el «deterioro» de la lengua común. Llaman la atención, en efecto, las dos metáforas descriptivas que con frecuencia se emplean en ámbito «dardesco»: la lengua es «patrimonio» y es «instrumento». Porque estas metáforas denuncian, a raíz de las analogías implícitas que las sustentan, una concepción utilitarista y economicista de la lengua: esta es

13 Es una pena que a Miguel no se le ocurriera (o no le fuera posible) consultar las ediciones del diccionario académico correspondientes al período por él investigado (cuatro ediciones: 1899, 1914, 1925, 1936). Por lo pronto, habría descubierto que muchas de las definiciones que comenta (galante, lengua, liga, seducir, viso) han llegado prácticamente inalteradas hasta la edición de 1992. 
«propiedad» de todos y sirve solo si todos la «empleamos» de la misma forma. La lengua se reifica, por lo tanto, convirtiéndose en una seña de identidad y en un instrumento de auto-perpetuación del orden social.

El orden burgués [cualquier orden] no puede dejar el lenguaje al azar. Hay que codificarlo para que dé apariencia de orden y de previsión normativa. No es casualidad que la Gramática de Nebrija se corresponda con el mismo espíritu humanista con que Erasmo de Rotterdam o Luis Vives escribieron sobre las costumbres de su tiempo. Hay que hablar bien y comportarse bien (MIGUEL, 1991: 90).

¿Quién decide, sin embargo, acerca de lo que está o no está bien? ¿La multitud? ¿La elite? ¿Alguna asamblea de expertos? ¿Y siguiendo qué criterios? «¿Una conducta que se generaliza es por ello legítima?» se pregunta Miguel (1991: 95): «Los aires democratizadores de nuestro tiempo tienden a forzar una respuesta afirmativa. No me parece oportuna esa ampliación automática de la idea de democracia a tales supuestos». Sobre todo porque, como ya apuntara Lázaro Carreter y luego recogería Grijelmo, la laxitud y la indolencia imperan.

Volvemos a las andadas. Algunos intelectuales se empecinan en sostener que los hablantes, en general, deberíamos empeñarnos más y mejor en el uso del idioma, respetando sus normas, hábitos y tradiciones. Otros, en cambio, recuerdan que somos los hablantes los que definimos, con nuestra actividad, la norma, el hábito y la tradición. «Lo cierto es que muchas de las aparentes incorrecciones [en el uso de la lengua] —escribe Bernárdez (2012: 48)- son cambios en marcha y muchas de ellas tienen una clara utilidad». Estoy de acuerdo. Pero no siempre las rotundas afirmaciones de este autor (como las de Grijelmo, en efecto, si bien de signo contrario) me parecen tan acertadas. «Lo que existe son los hablantes - sigue Bernárdez (2012: 52)-, y ellos son los únicos que tienen derecho a establecer la norma y el estándar, y los únicos con capacidad de hacerlo. Lo demás son majaderías propias del pensamiento aristocrático del siglo XVIII». Majadería o no, me parece legítimo defender que ningún hablante tiene el derecho (ni, por lo común, la posibilidad) de hablar y escribir en total libertad, así como se le antoje, ya que la lengua, para parafrasear una famosa sentencia de Roland Barthes, siendo actividad de muchos, a la postre sí que resulta ser un poco fascista ${ }^{14}$. ¿Que los idiomas se autoorganizan? Vale. Pero no podemos olvidar que los hablantes interaccionan continuamente de manera metalingüística —es decir, hablan de cómo hablan, sobre todo cuando surgen problemas de comprensión

14 «La estructura obliga», según recuerdan (con fines polémicos muchos más radicales que la defensa de un estándar lingüístico) los biólogos chilenos Humberto Maturana y Francisco Varela (2003: 155), refiriéndose precisamente al lenguaje, los organismos que en él derivan y sus formas de convivencia: «La estructura obliga. Los humanos como humanos somos inseparables de la trama de acoplamientos estructurales tejida por la «trofolaxis» lingüística permanente. El lenguaje no fue nunca inventado por un sujeto solo en la aprehensión de un mundo externo, y no puede, por lo tanto, ser usado como herramienta para revelar un tal mundo. Por el contrario, dentro del lenguaje mismo el acto de conocer, en la coordinación conductual que el lenguaje es, trae un mundo a la mano. Nos realizamos en un mutuo acoplamiento lingüístico, no porque el lenguaje nos permita decir lo que somos, sino porque somos en el lenguaje, en un continuo ser en los mundos lingüísticos y semánticos que traemos a la mano con otros. Nos encontramos a nosotros mismos en este acoplamiento, no como el origen de una referencia ni en referencia a un origen, sino como un modo de continua transformación en el devenir del mundo lingüístico que construimos con los otros seres humanos». 
e intercomprensión y también desde sus diferentes ideales de «pulcritud idiomática»- y lo hacen en el ámbito de múltiples redes, más o menos estructuradas y jerarquizadas, de actividades lingüísticas de tipo estándar (la familia, los amigos, la escuela, el trabajo, internet, los libros, etc.). Así pues, si existe la autoridad de la Academia, lo único que cabe concluir es que son los mismos hablantes quienes la legitiman: el diccionario de la RAE (ahora también de la ASALE) es probablemente, hoy día, la obra lexicográfica española más consultada en los países de habla hispana y en el mundo (por más deficientes, desfasadas y anacrónicas que resulten muchas de sus definiciones y cómplice su disponibilidad en línea ${ }^{15}$ ). En otros términos: la Academia y el Diccionario de la lengua española, se acaten o rechacen sus consignas (empezando por la de «limpiar, fijar y dar esplendor» hasta llegar a la de «conservar el genio propio de la lengua»), no son elementos externos, sino internos al proceso de autoorganización del idioma español (o castellano, lo mismo da). Ciertamente el español (o castellano) seguiría existiendo si la Academia cesara todo tipo de actividad, así como existía antes de su fundación y así como existen lenguas que no cuentan con ninguna corporación de especialistas que las dirija «desde arriba», pero una cosa es sostener que la Academia es una institución contingente (y al límite prescindible), otra muy distinta defender que es también inútil o perjudicial ${ }^{16}$.

Las definiciones y la composición del diccionario académico, según me consta, pueden mejorar y, en ocasiones, han ido mejorando. Por un lado, se acogen nuevas voces y nuevas acepciones, quizás hostigadas con anterioridad por los defensores del «genio de la lengua». El propio Lázaro Carreter, en la introducción a El dardo en la palabra, tras subrayar «lo inseguro de los fenómenos [lingüísticos] observables en un momento dado, que pueden desparecer o asentarse en muy poco tiempo», reconoce sin ambages que, «de hecho, algunos vocablos cuyo empleo criticaba antes de 1992, aparecieron registrados en el diccionario académico de ese año; y tal vez con mi voto favorable» (LÁZARO CARRETER, 2003: 27) ${ }^{17}$.

Por otro lado, se intenta actualizar y acercar las definiciones al uso contemporáneo. Muchas de las incoherencias y anacronismos que Amando de Miguel, por ejemplo, achacaba a las definiciones académicas en la primera edición de La perversión del lenguaje (de 1985) fueron subsanadas en la siguiente edición del Diccionario, así como señala el propio autor: «queda como consuelo que muchas de las críticas que contenía la primera edición de este libro al Diccionario de la Real Academia de 1984 han sido asumidas por la nueva edición del DRAE, de 1992» (MIGUEL, 1994: 19).

15 Según una noticia publicada el 14.5.2020 en el portal digital de la Real Academia Española (www.rae.es), «el Diccionario de la lengua española (DLE) ha registrado en el último mes 100 millones de consultas en su versión en línea, logrando así un récord absoluto».

16 Naturalmente, el uso indiscriminado de cualquier autoridad sí puede acarrear perjuicios. Yo mismo me he visto afectado por aquellos evaluadores o reseñadores que reprenden el uso de un vocablo (uso técnico o creativo) porque no se corresponde con lo indicado en el diccionario académico.

17 El paso del tiempo y la deriva idiomática han desmentido muchos de los arrebatos reprensores (cuando no censores) de don Fernando (STRBAKOVA y LAMPIS, 2013). Me parece, con todo, que sigue muy válida y actual la crítica del insigne filólogo a la excesiva laxitud y despreocupación de los profesionales de la palabra a la hora de desempeñar su labor. 
Las voces del eros no constituyen ninguna excepción. De hecho, en las últimas dos ediciones del Diccionario, la vigésima segunda de 2001 y la vigésima tercera de 2014, se han hecho pasos considerables para volver más neutrales y comprehensivas muchas de las voces relacionadas con el sexo y la sexualidad (LAMPIS, 2020в). En este sentido, por lo tanto, cabe concluir que la «pudibundez» del diccionario académico está sin duda menguando, a raíz de los dos factores indicados más arriba: una mayor libertad o liberalidad en las prácticas y los discursos acerca de la sexualidad (o una sociedad menos sexófoba, si se prefiere) y una práctica lexicográfica que tiende, cada vez más, a la neutralidad axiológica.

Me parece un acierto considerable, por parte de Miguel, el haber incluido con contundencia (e ironía) en el género «dardesco» el problema del desfase existente entre el léxico del diccionario académico y el léxico de los hablantes. Pero acerca de este desfase es recomendable la misma prudencia teórica y metodológica que hay que guardar a la hora de tratar cualquier cuestión relacionada con los procesos centrípetos y centrífugos que actúan sobre el idioma. En el caso concreto del Diccionario de la lengua española de la RAE (ahora también de la ASALE), a pesar de la legitimidad de muchas de las acusaciones de conservadurismo y anacronismo que se le dirigen, lo cierto es que siempre nos aguarda una nueva, futura edición y la consiguiente posibilidad de acercar un poco más la tortuga a Aquiles. Tiempo al tiempo.

\section{AGRADECIMIENTOS}

Este artículo se inscribe en el proyecto de investigación «Semiótica del eros. Erotismo y textualidad en las culturas de lengua románica» (proyecto VEGA, n. 1/0292/19).

\section{REFERENCIAS BIBLIOGRÁFICAS}

BERnÁrdez, EnriQue (2012): ¿Qué son las lenguas?, Madrid, Alianza.

Cela, Camilo José (1994): Enciclopedia del erotismo, Madrid, Grupo Libro 88.

Grijelmo, Álex (2001): Defensa apasionada del idioma español, Madrid, Santillana.

LAmpis, Mirko (2020a): «Verso una semiotica dell'eros», E/C. Rivista on-line dell'AISS Associazione Italiana Studi Semiotici, http://www.ec-aiss.it/archivio/tipologico/saggi.php, acceso 5/8/2020.

- (2020b): «Hacia una semiótica del eros. El aspecto lexicográfico. Los diccionarios de la lengua española», Revista Chilena de Semiótica, 13, pp. 164-181, https://www.revistachilenasemiotica.cl/ numero-13/, acceso 1/9/2020.

Lázaro Carreter, Fernando (2003): El dardo en la palabra, Barcelona, Random House Mondadori.

Maturana, Humberto, y Francisco Varela (2003): El Árbol del Conocimiento. Las bases biológicas del entendimiento humano, Buenos Aires, Lumen.

Miguel, Amando De (1991): Cien años de urbanidad. Crítica de costumbres de la vida española, Planeta, Barcelona.

- (1994): La perversión del lenguaje, Madrid, Espasa Calpe.

- (1998): El sexo de nuestros abuelos, Madrid, Espasa Calpe.

- (2013): Hablando pronto y mal, Madrid, Espasa. 
NARBona JimÉneZ, Antonio (2001): «Movimientos centrífugos y centrípetos en la(s) norma(s) del español», II Congreso Internacional de la Lengua Española. El español en la sociedad de la información. Unidad y diversidad del español: la norma hispánica, Valladolid, 2001, http://congresosdelalengua.es/valladolid/ponencias/unidad_diversidad_del_espanol/1_la_norma_hispanica/ narbona_a.htm, acceso 22/11/2020.

Real Academia Española (1992): Diccionario de la lengua española. Vigésima primera edición. En Nuevo Tesoro Lexicográfico de la Lengua Española, http://ntlle.rae.es/ntlle/SrvltGUILoginNtlle, acceso 5/8/2020.

- (2001): Diccionario de la lengua española. Vigésima segunda edición. https://www.rae.es/ drae2001, acceso 5/8/2020.

Real Academia Española y Asociación de Academias de la Lengua Española (2014): Diccionario de la lengua española. Vigésima tercera edición. https://dle.rae.es, acceso 5/8/2020.

Rodríguez GonzÁlez, Félix (2011): Diccionario del sexo y del erotismo, Madrid, Alianza.

Seco, Manuel, Olimpia Andrés y Gabino Ramos (1999): Diccionario del español actual, Madrid, Aguilar.

Strbakova, Radana, y Mirko Lampis (2013): «Los extranjerismos en los dardos de Fernando Lázaro Carreter: entre norma y uso, homogeneidad y diversidad», Diversidad lingüística del español, eds. M. Vales y S. Mica, Universidad técnica de Liberec, pp. 69-98. 